\title{
The Battle of Superheroes: The Rise of the Knowledge Platform \\ Strategy in the Movie Industry
}

\author{
Daniel TRABUCCHI \\ (corresponding author) \\ Politecnico di Milano \\ School of Management \\ daniel.trabucchi@polimi.it \\ Stefano MAGISTRETTI \\ Politecnico di Milano \\ School of Management \\ stefano.magistretti@polimi.it
}

This is the post-print version of the paper published on the Journal of Knowledge Management please cite as

Trabucchi, D., and Magistretti, S. 2020. "The Battle of Superheroes: The Rise of the Knowledge Platform Strategy in the Movie Industry", Journal of Knowledge Management. 10.1108/JKM-04-2020-0296

\begin{abstract}
Purpose: Over the last years - thanks to the huge impact of companies like Airbnb and Uber - the concept of platform became extremely popular in the business world. Still, the concept of platform has been evolving for a long time in the management field, from internal platforms (like the famous case of Sony Walkman), to industry-wide platforms (like the case of computers with external software developers), up to transaction and two or multi-sided platforms (like Airbnb and all the companies with a similar business model).

Platforms are often considered disruptors in several industries, from accommodations to mobility to entertainment. Still, the disruptors in the creative world usually deal with the way in which they distribute content (Netflix or Spotify), rather than with the content itself. Can platform strategies also be used in creative industry?

Design/Methodology/Approach: This article digs into the movie industry, studying the three most successful Superheroes sagas of the last two decades: the Marvel Cinematic Universe, DC Comics and X-Men using a narrative approach. The three sagas are studied through network analysis to understand their "platform approach".
\end{abstract}


Findings: Our results show how platform strategies are relevant also in creative industries defining the concept of "Knowledge Platform Strategy" - and how they have a significant impact in terms of market performance. The Marvel Cinematic Universe builds on a common knowledge through the various movies that enable the chance to rely on many of the platforms' characteristics emerging from the literature.

Research limitations/Implications: This research extends the concept of "platforms", relying on the three kinds of platform defined in the managerial literature and introducing the "Knowledge Platform Strategy" for creative industries. The main contribution is related to the extension of platforms in research fields where it has not been exploited. This opens up avenues for research both from a knowledge platform and creative industries perspectives.

Practical implications: Managers, working in creative industries, but also in industries where a common knowledge basis may be leveraged to develop new products over time, may use the concept of "Knowledge Platform Strategy" to rethink the new development process or knowledge management from a customer perspective.

Originality/value: This study explores a mature and relevant concept - the platforms - in a new filed, the creative industries using the case of Superheroes sagas, proposing a new perspective to explain the success of MCU, while proposing a new platform strategy.

\section{Keywords}

Platforms; Network Effects; Creative Industries; Knowledge Strategy; Business Model

\section{Classification}

Research paper 


\section{Introduction: Platforms Rule the World}

We live in the era of the "Platform Revolution" (Choudary et al., 2016). Every day we get in touch with platforms that aim to make our life easier, or frictionless (Evans and Schmalansee, 2016). "Platforms" are all those companies that put together people, organizations and resources in an interactive ecosystem, where the flows of value creation and capturing may overrule significantly (Choudary et al., 2016). Knowledge flows changed as well, since platforms are also changing the interaction among peers, like in social networks (e.g., Antonacci et al., 2017), or among seekers and solvers in crowdsourcing initiatives or innovation intermediaries (e.g., Randhawa et al., 2017; Malhotra and Majchrzak, 2020) Just a couple of years ago, our reality was a dystopic future world. Today, we can get a ride from a stranger, sleep in the bed of an ordinary person and drive a car that we don't own without asking anyone. These are just simple examples of how platforms have entered our daily lives and enable us to do previously unimaginable things.

Platforms are having a disruptive impact on many industries by challenging the status quo and changing the rules of the game in an unpredictable way (Downes and Nunes, 2014).

The music industry has changed significantly in the last 20 years (Kaplan and Haenlein, 2010) because of how first iTunes and then Spotify changed the rules of the game. Profits are spread in a different way, and the physical distribution network is almost worthless. They changed how people enjoy and discover music (Trabucchi et al., 2017; Artusi and Bellini, 2020).

The mobility industry is facing the opportunities and challenges derived by new technologies like autonomous driving, but in the meantime, it must contend with the new behaviors of people. Initiatives like Car2Go, oFo or Lime offer new ways for people to get around in cities. 
Airbnb or BlaBlaCar are showing new opportunities for travelers, who can now decide to not use the traditional offering of hotels, bed and breakfasts and other accommodation providers, or even to not use traditional services to move from one city to another.

Netflix - and all the other streaming services that followed over the years - provides people the chance to see what they want, when they want it. This is a huge challenge for traditional providers like TV broadcasters that saw their market positions go through significant pressure. The list of examples can continue further to include a lot of other industries, sectors and kinds of businesses.

This study focuses on the creative industries (e.g., Savino et al., 2017; Latilla et al., 2018, 2019), which are often involved in the platform industries through giants like Spotify and Netflix. Nevertheless, these cases mainly work on how creative content is distributed. Taking a literature based perspective, there are early evidence showing how companies in the creative industries - like Netflix for example - are leveraging platforms logic in the early phases of content development, for example using big data analytics to understand viewers' behaviors and deciding what to produce next (Verganti et al., 2020). Co-creation platforms have been highly studied and used to enhance co-creation and collaboration involving endusers or to get in touch with other content creators (Saragih, 2019). Similarly, platforms influenced the business model of creative firms, for example creating distributed platforms to develop and test new solutions (Landoni et al., 2020).

But what about the content? Can platform dynamics also enhance the content of the final product or are they just concerned with distribution or creation process? Can the knowledge flow typical of a platform influence the content in a creative industry?

Considering the movie production field, we can see how over the last decades something significant has happened. The number of movies that yearly made more than $\$ 1$ billion has 
increased year by year, moving from being a rare event to something quite common (IMDB, 2019). Forty-six movies have reached this goal in the cinema history, 37 of which just in the last decade (Renfro, 2020). Among them, the vast majority has a common denominator: the Walt Disney Company. However, there is something else clearly emerging on top of the others. The Top 5 has two new entries in the last two years: "Avengers: Infinity War" in 2018 and "Avengers: Endgame" in 2020. The franchise led by Iron Man has had a great run over the last years, with 9 movies in the list since 2012.

The Marvel Cinematic Universe is one of the closest things to the concept of "disruption" in the movie industry (Harrison et al., 2019): 22 movies for $\$ 17$ billion at the box office, with an $84 \%$ rating on Rotten Tomatoes and 64 nominations and awards. Their movies build one on the others, creating and expanding universe that expands movie after movie. Each of them builds on what has been previously introduced in the storyline, creating opportunities that seem interesting both from a storytelling perspective and from a business perspective. This idea of "building" on a common base is typical of the platform dynamics (Gawer and Cusumano, 2014). Is Marvel a platform-based disruptor? Can we consider the chance to link all the movies and to build one on the other in a platform-strategy? And on top of that, would a platform strategy lead to better results in a creative industry like Hollywood?

This article aims to unveil the power of platforms in the creative industries, studying one of the most grossing genres of the last decades: superhero movies (Salkowitz, 2018). Answering to these questions may bring to two contributions. On the one hand, it may use the platforms has an explanation of the extreme success of the Avengers case. On the other, we may expand the concept of platforms bringing it within the concept development, enhancing is contributions in different fields from where it usually applies. 


\section{Theoretical Background: The Superpowers of Platforms}

Over the last decade, management literature has seen a huge evolution of the concept of platforms.

Originally, it was used in the field of new product development. The term was used to describe those projects that were based on a shared architecture that would enable the creation of a number of derivative products (Wheelwright and Clark, 1992; Kogut and Kulatilaka, 1994; Kim and Kogut, 1996; Meyer and Lehnerd, 1997). The main idea was to create a common basis on top of which the firm had the chance to foster innovation in a faster and cheaper way. This was later defined as an "internal platform" (Gawer and Cusumano, 2014). The greatest opportunities of this "platform approach" are to spread the investment on multiple products, while making the development process shorter and less expensive.

One of the greatest examples in Sony, that created 279 models based on only five different platforms, helping them to spread to every market niche in an effective and efficient way (Sanderson and Uzumeri, 1995).

Over the years, this concept evolved, reaching the definition of "industry-wide platform" (Gawer and Cusumano, 2014). Great examples like the alliance of Microsoft, Intel and IBM showed that the power of platform may move single companies forward. Indeed, by putting together the hardware, the processor and the software, these three companies created something like an internal platform, and then they opened it up. In other words, they started having complementors. This means that the platform may be used to foster innovation not only by the companies that created it, but by anyone willing to foster something new by leveraging the existing base. In other words, the platform is a knowledge base upon which various players can build on, this led to the creation of applications by external developers. 
Or, more broadly, also social networks and virtual communities may be part of this classification (e.g., Antonacci et al., 2017).

Similar approaches have been used by game console makers or by smartphone providers with the creation of app stores. These cases have a lot of similarities with two-sided markets (Rochet and Tirole, 2003), having two different groups of customers (sides, the end users and the developers) that are joined by a platform (Windows, PlayStation or iOS) generating network effects (Brillinger et al., 2020). In particular, they generate indirect or cross-side network externalities (Katz and Shapiro, 1985), which means that the more players join one side (e.g., the more gamers Playstation has) the more the platform (Playstation) will be valuable for the other side (developers) and vice versa. Over the years, academics stopped using the term "two-sided markets" and started preferring the more flexible "multi-sided platforms" (Hagiu and Wright, 2015 Täuscher, 2017), which refers to all those businesses that put together multiple customers through indirect network externalities.

Very recently, Cusumano and colleagues proposed a way to clearly distinguish between these concepts re-labeling "industry-wide platforms" as "innovation platforms" and considering all the other multi-sided platforms as "transactional platforms" (Cusumano et al., 2019). Basically, "innovation platforms" refer to all those platforms open to external players that can leverage that common basis to foster innovation, while "transactional platforms" are all those businesses that put together various sides as main value propositions, like many of the examples previous mentioned (Spotify, Airbnb, and many more) (Trabucchi and Buganza, 2020).

Over the last years, academic- and practitioner-oriented literatures have paid a lot of attention to these platforms, which have been highly boosted by the spread of digital technologies, since these are highly appreciated by investors (Trabucchi et al., 2019; Sanasi 
et al., 2020). Moreover, this kind of platforms has been highly studied in the field of crowdsourcing, matching people asking and offering knowledge on given topics (e.g., Randhawa et al., 2017; Malhotra and Majchrzak, 2020)

Platforms emerged as a new business model (Amit and Han, 2017), for various reasons, and offering various opportunities.

One of these opportunities is that platforms can scale fast to gain a wide diffusion in a short amount of time by leveraging the power of digital technologies (Magistretti et al., 2019). This is often related with the chance to rely on a zero-marginal cost structure (Rifkin, 2014), which enables them to reach a worldwide diffusion and huge number of customers quickly (Choudary et al., 2014).

Still, the basic structure of platforms embeds the concept of modularity (Baldwin and Clark, 2003), having smaller "components" or "phases" which may offer flexibility. This means having the chance to add sides over time, fostering innovation on transactional platforms and adding new services to the span of activities offered, like Uber Eats for Uber or Experiences for Airbnb (Trabucchi and Buganza, 2020).

Finally, platforms offer interesting opportunities in terms of value capturing, having the chance to have multiple revenue sources and to subsidize some of the sides (Parker and Van Alstyne, 2005).

Unfortunately, not all that glitter is gold, and platforms also face several challenges, with a number of downsides.

First, setting up a platform is anything but simple. Internal and industry-wide platforms require large investments, but transactional platforms suffer the so-called chicken and egg paradox (Caillaud and Jullien, 2003). The platform is - initially - worthless until it has customers. Nevertheless, to bring on board one side, the other one should be already on 
board. Various tactics exist to solve this, but it remains one of the most challenging phases of the platform lifecycle (Trabucchi, 2020).

Similarly, to reach the critical mass to start the network effects is not an easy job, and actually represents the most common fatal error (Evans and Schmalansee, 2010). Indeed, once the players are on board, the platform provider needs to craft ad hoc value propositions for each side, making the business model design a much more complex process, rather than in traditional linear value chain businesses (Muzellec et al., 2015).

Despite the various kinds of platforms that have been defined in the literature, all of them share a common element: there is a common basic structure upon which it is possible to build something bigger. This ability to "plug-and-play", to create on top of something has been defined as "Platform Thinking" or "Platform strategy" (Bonchek and Choudary, 2013).

Leveraging and building on the platforms literature (summarized in its various perspectives in Table 1) - in their various definitions - this study aims to understand if and how a platform strategy may be applied in creative industries (e.g., Savino et al., 2017; Latilla et al., 2018, 2019). In other words, we aim to understand if the typical mechanisms of platforms may take place also in creative industries and if one of the various platforms better fits than the others or if a hybrid approach may emerge.

\begin{tabular}{|l|l|l|}
\cline { 2 - 3 } \multicolumn{1}{c|}{} & \multicolumn{1}{c|}{ Examples } & \multicolumn{1}{c|}{ Main References } \\
\hline $\begin{array}{l}\text { Internal or product } \\
\text { platforms }\end{array}$ & $\begin{array}{l}\text { Sony creating the various } \\
\text { versions of the Walkman } \\
\text { upon 5 basic architectures }\end{array}$ & $\begin{array}{l}\text { Wheelwright and Clark, 1992; } \\
\text { Meyer and Lehnerd, 1997; } \\
\text { Gawer and Cusumano, 2014 }\end{array}$ \\
\hline $\begin{array}{l}\text { Industry-wide or } \\
\text { innovation } \\
\text { platforms }\end{array}$ & $\begin{array}{l}\text { IBM, Microsoft and Intel } \\
\text { offered personal computers } \\
\text { where external } \\
\text { complementors offer } \\
\text { software }\end{array}$ & $\begin{array}{l}\text { Gawer and Cusumano, 2014; } \\
\text { Cusumano et al., 2019; } \\
\text { Brillinger et al., 2020 }\end{array}$ \\
\hline $\begin{array}{l}\text { Multi-sided or } \\
\text { transaction } \\
\text { platforms }\end{array}$ & Airbnb, Uber & $\begin{array}{l}\text { Gawer and Cusumano, 2014; } \\
\text { Hagiu and Wright, 2015; } \\
\text { Cusumano et al., 2019; } \\
\text { Trabucchi and Buganza, 2020 }\end{array}$ \\
\hline
\end{tabular}


Table 1 - Summary of types of platformsResearch Design and Methodology:

\section{Superheroes are a Powerful Source of Evidence}

\section{Empirical setting}

Creative industries are defined as those sectors where knowledge and creativity are shared among different clusters of people. Inside the vast variety of creative sectors, we selected the film industry because it perfectly fits with the aim and scope of the investigation. Indeed, the idea of understanding how platform solutions can be designed outside the digital environment, and especially how they can be adopted by creative industry, guided us in selecting the movie industry where different strategies seem to emerge.

As previously mentioned, the last decade saw the rise and the consolidation of a relevant phenomenon: the MCU, namely the Marvel Cinematic Universe, which had a relevant impact on the box office (IMDB, 2020).

Nevertheless, superheroes are not just from the MCU; there are three relevant players in the field that seem to leverage different strategies.

The three players here considered are The Walt Disney Company, $20^{\text {th }}$ Century Fox (acquired by The Walt Disney Company in 2019) and Warner Bros. In more detail, we considered three media franchises initiatives put in place by the three players: the MCU by The Walt Disney Company, the X-Men series by $20^{\text {th }}$ Century Fox and the DC Comics movies and the related Extended Universe by Warner Bros (starting from Catwoman in 2004, as the first "modern" superhero movie in the new century). Table 2 summarizes the movies considered for each franchise.

\begin{tabular}{|c|c|c|c|c|c|}
\hline \multicolumn{2}{|c|}{ Marvel Cinematic Universe } & \multicolumn{2}{|c|}{ X-Men Series } & \multicolumn{2}{c|}{ DC Movies } \\
\hline Year & Movie & Year & Movie & Year & Movie \\
\hline 2008 & Iron Man & 2000 & X-Men & 2004 & Catwoman \\
\hline
\end{tabular}




\begin{tabular}{|c|c|c|c|c|c|}
\hline 2008 & The Incredible Hulk & 2003 & X-Men 2 & 2005 & Constantine \\
\hline 2010 & Iron Man 2 & 2006 & $\begin{array}{l}\text { X-Men: The Last } \\
\text { Stand }\end{array}$ & 2005 & Batman Begins \\
\hline 2011 & Thor & 2009 & $\begin{array}{l}\text { X-Men Origins: } \\
\text { Wolverine }\end{array}$ & 2006 & Superman Returns \\
\hline 2011 & $\begin{array}{l}\text { Captain America: The } \\
\text { First Avenger }\end{array}$ & 2011 & X-Men: First Class & 2008 & The Dark Knight \\
\hline 2012 & The Avengers & 2013 & The Wolverine & 2009 & Watchmen \\
\hline 2013 & Iron Man 3 & 2014 & $\begin{array}{l}\text { X-Men: Days of } \\
\text { Future Past }\end{array}$ & 2010 & Jonah Hex \\
\hline 2013 & Thor: The Dark World & 2016 & Deadpool & 2011 & Green Lantern \\
\hline 2014 & $\begin{array}{l}\text { Captain America: The } \\
\text { Winter Soldier }\end{array}$ & 2016 & X-Men: Apocalypse & 2012 & The Dark Knight Rises \\
\hline 2014 & $\begin{array}{l}\text { Guardians of the } \\
\text { Galaxy }\end{array}$ & 2017 & Logan & 2013 & Man of Steel \\
\hline 2015 & $\begin{array}{l}\text { Avengers: Age of } \\
\text { Ultron }\end{array}$ & 2018 & Deadpool 2 & 2016 & $\begin{array}{c}\text { Batman v Superman: Dawn } \\
\text { of Justice }\end{array}$ \\
\hline 2015 & Ant-Man & 2019 & Dark Phoenix & 2016 & Suicide Squad \\
\hline 2016 & $\begin{array}{c}\text { Captain America: Civil } \\
\text { War }\end{array}$ & & & 2017 & Wonder Woman \\
\hline 2016 & Doctor Strange & & & 2017 & Justice League \\
\hline 2017 & $\begin{array}{c}\text { Guardians of the } \\
\text { Galaxy Vol.2 }\end{array}$ & & & 2018 & Aquaman \\
\hline 2017 & $\begin{array}{l}\text { Spider-Man: } \\
\text { Homecoming }\end{array}$ & & & 2019 & Shazam! \\
\hline 2017 & Thor: Ragnarok & & & 2019 & Joker \\
\hline 2018 & Black Panther & & & & \\
\hline 2018 & Avengers: Infinity War & & & & \\
\hline 2018 & $\begin{array}{c}\text { Ant-Man and the } \\
\text { Wasp }\end{array}$ & & & & \\
\hline 2019 & Captain Marvel & & & & \\
\hline 2019 & Avengers: Endgame & & & & \\
\hline 2019 & $\begin{array}{l}\text { Spider-Man: Far from } \\
\text { Home }\end{array}$ & & & & \\
\hline
\end{tabular}

Table 2 - Movies in the sample and release year Superhero franchises seem to be a proper field where it is possible to study the potential impact and nature of platform strategies in the creative industries. Indeed, all three franchises can be considered successful from a market perspective and seem to apply different strategies from a platform perspective.

In particular, the MCU is gaining colossal relevance in the sector for its ability to create a central saga like The Avengers. In this saga, different superheroes play a role even if the story of the character is developed outside and sometimes independently by the Avengers saga itself. Thus, the Marvel Cinematic Universe strategy may seem like a platform initiative where different movies build both independent and common stories building on other movies. In other words, new movies do not build everything from scratch. They have a strong common basis (platform) to be leveraged. 
On the contrary, DC Comics, with various sagas (such as Batman, Superman, and a number of stand-alone movies like Catwoman or Wonder Woman), seem to pursue a traditional "new product development" strategy, keeping each different initiative separated from the others. Finally, the X-Men series seems to be a hybrid solution: all movies are related to all the others, but in the same way, they figure as a long list of sequels.

The goal of this study is twofold. Firstly, we want to test the assumptions we made on the three cases. Are these three cases leveraging different platform strategies? Secondly, is there any kind of correlation between platform strategies and the impact on the box office?

\section{Narrative method}

The research is approached through the narrative method, which is an interpretive description of historical facts aiming to give meaning to a series of events (Gabriel, 2000). The main goal of these studies is to provide an explanation to a phenomenon taking a process perspective, showing how things lead there (Pentland, 1999). This is highly coherent with our study, trying to understand what brought to the emergence of the Avengers case, searching for common points with the concept of platform. From a research perspective, a number of key events need to be highlighted and the links among them (Garud et al., 2014). Usually narrative studies focus of one or more cases, aiming for a depth understanding or the chance to provide similarities and difference (Andriani and Carignani, 2014; Franzoni and Sauremann, 2014; Beltagui et al., 2020).

Therefore, secondary sources have been used to recreate the development of three franchises, the links between the movies and their market results.

\section{Data gathering and data analysis}


First, we clustered all the different films that belonged to the different franchises to be sure that no film belonging to them was excluded from the analysis. Second, we looked for the box office results achieved by the various franchises. In so doing, we referred to websites like Box Office Mojo, The Numbers, IMDb, and Rotten Tomatoes recognized in the industry as references for this kind of information. After this, we looked at the different elements inside each film that could have highlighted an existing link among the different elements. In the first part of this step, we analyzed the appearance of characters in different movies of the franchise. Then, we analyzed the locations that appear in the movies and lastly, we looked at the items that recur in the different movies.

The identification of such repeated elements inside the different movies allowed us to analyze the different initiatives by seeing the connections and links among the different aspects. As suggested by Miles and Huberman (2002), we qualitatively analyzed the information by first clustering it and then understanding its value.

To asses is the three franchises rely or not on a platform strategy, we used network analysis. Network Analysis (or Social Network Analysis) is an interdisciplinary methodology developed by sociologists and researchers in social psychology in the 1960s and 1970s, further developed in collaboration with mathematics and statistics, that led to a rapid development of formal analysis techniques which made it an attractive tool for other disciplines like economics, marketing or industrial engineering (Scott, 2000). The main assumption Is related to the fact that the relationships among interacting units (the nodes of the network) have an important role to interpret the behaviour of the actors in the network. The relations between the nodes are the fundamental component of network analysis. Originally, nodes were "social" entities (individuals, teams or organizations), even though the diffusion of the method brought also the use of products or firms as nodes (Baldwin and Woodard, 2009). 
Network analysis is mainly related to two perspectives: the network structure and the role of a nodes within the network. The first perspective considers measure like graph density or the modularity, which is the presence of sub-groups, aiming to study the set of ties linking all the nodes (Wasserman and Faust, 1994). The second perspective focuses on the role of the nodes in spreading information, knowledge or influence (Watts, 2003). The main metrics are the centrality (how much a node is linked with the others) or the betweenness (how much a node act as a bridge between other nodes).

Network analysis over the last years got a significant attention in the management literature, specifically in the innovation (Arenas-Márquez et al., 2014; Hu et al. 2015) and knowledge management fields (Han et al., 2020; Su, 2020). Indeed, the most common method to represent a platform is to use networks, where each node is a platform or a product (Baldwin and Woodard, 2009; Pellizzoni et al, 2019). Networks can show different information such as how elements in the platform are more or less central, the number of complements and the evolution of the platform and complements over time. Platforms should have a denser and more structured network than "traditional" configurations.

This in-depth analysis of each film of the three franchises granted us the ability to create a network analysis and understand which connections exist between the various elements, also in a graphical view. Using Gephi, a popular software for network analysis in the management literature (e.g., Donthu et al., 2020), we analyzed the different network graphs searching for the commonalities and differences in the strategy adopted. Thus, we moved from qualitative analysis, the recognition of links among different movies (e.g., characters, locations, items) to the quantitative measures of them, so we summed up each relationship to see the strength of the connection between one movie and another. We then plotted these results with Gephi, and qualitatively interpreted them. Moreover, we calculated and considered the network 
density, the average degree centrality and the path length. These are the typical dimensions that connote a network graph. Finally, we ran an ANOVA with Post Hoc over the dataset to see potential statistical significance of the link existing between the strategy and the box office results achieved.

\section{Empirical Results: Marvel Cinematic Universe Rules Everyone}

The first analysis conducted aimed at understanding the results achieved by the different franchises at the Box Office (Figure 1).

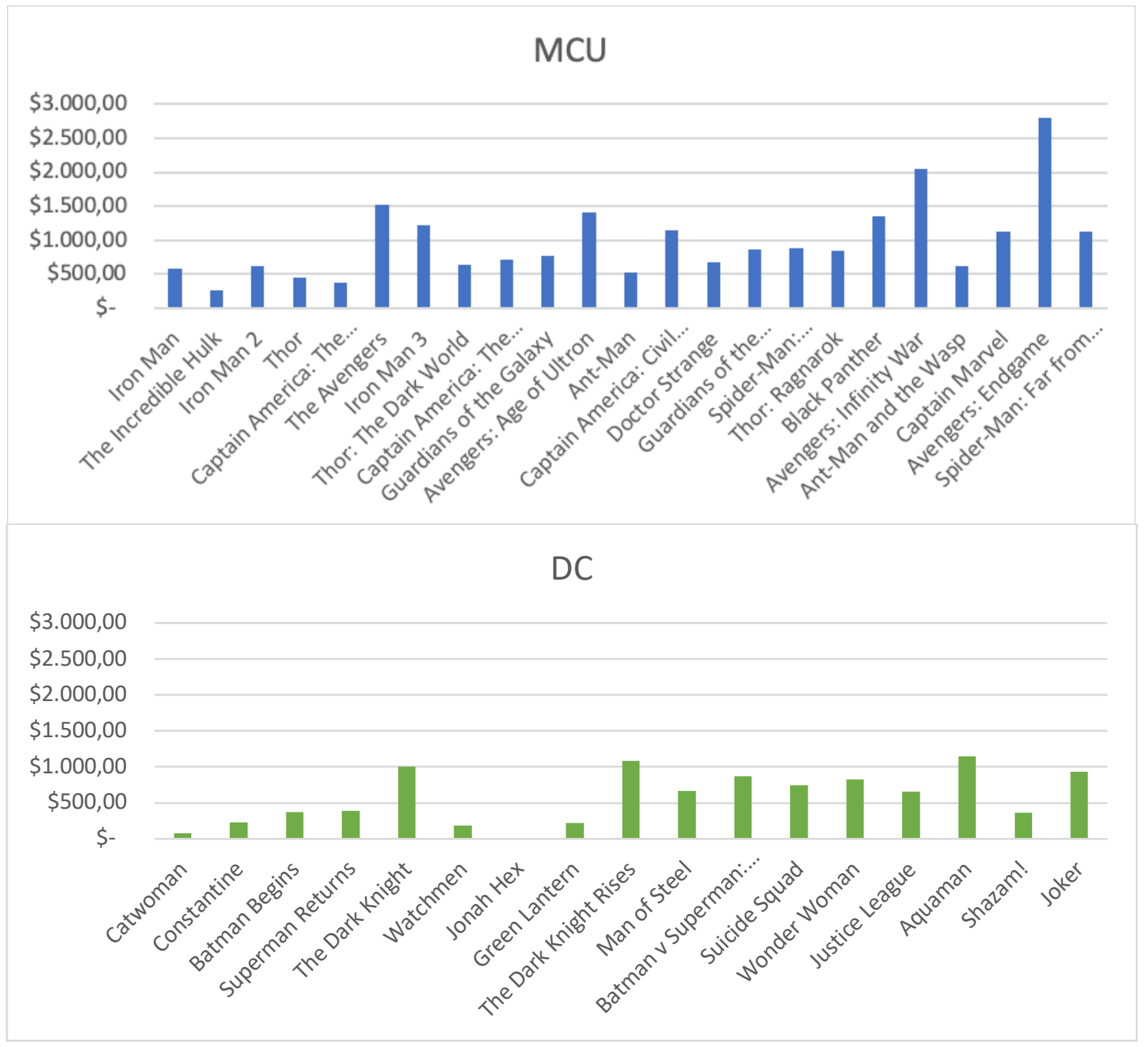




\section{X-Men}

$\$ 3.000,00$

$\$ 2.500,00$

$\$ 2.000,00$

$\$ 1.500,00$

$\$ 1.000,00$

$\$ 500,00$

$\$-$

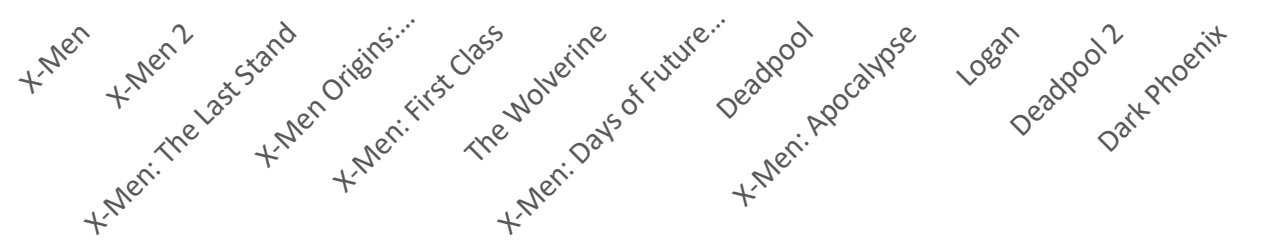

\section{Figure 1 - Box office results of the three cases}

What is interesting is that the economic and financial results obtained by each of the franchises analyzed are showing peculiar differences. First, if we look at the Marvel Cinematic Universe, we can see that it is showing the highest average box office income of almost 1.000 mln US dollars for each film, specifically $981.93 \mathrm{mln}$ US dollars. This is even more interesting if we consider that starting from 2008 up to 2019, Marvel released, on average, 1.9 films per year, and notwithstanding this, was able to have almost double the average income compared to the other two franchises considered. X-Men had an average box office revenue of $500 \mathrm{mln}$ US dollars in light of nearly one film every two years, so an occurrence of 0.5 films a year. Finally, DC shows an income a little bit higher than X-Men but lower than Marvel, averaging $584.57 \mathrm{~m} / \mathrm{n}$ US dollars for an average release of around 1.1 films per year.

The numbers mentioned above shows some impressive results. During the last three years (2017-2019), Marvel launched three films per year with a box office average if over $1.200 \mathrm{mln}$ US dollars. This is interesting because it shows how launching more films does not cannibalize the box office if the strategy adopted is appropriate. The amount of $1.200 \mathrm{~m} / \mathrm{n}$ US dollars is more than the peak of DC's most watched movie, Aquaman, which reached $1.148 \mathrm{mln}$ US 
dollars at the box office. Thus, understanding more about how this success was reached is of interest for both practitioners and academics.

After the analyzing box office results for each of the three franchises, we dug deeper into the strategy adopted to build the different stories and films. When choosing a network analysis, we looked at the three initiatives to see the existing connections between the various elements inside each franchise. What came out for the study was both the existence of these links and the intensity of them. Thus, how many characters, locations, and items from the movie are present in the various movies was mapped for each franchise. In this way, we did not only search for the link, but we also looked at the strength of the network. Finally, we represented these networks graphically to give evidence of the results achieved.

\section{The Avengers' supremacy}

Starting from the MCU, we searched for connections between characters, locations, and items that recur in different movies. The development of movies is highly based on the knowledge introduced in the previous ones. What is evident from Figure 2, which shows the three results of the network analysis on characters, locations, and items, is that all the films are somehow related and linked and that the four Avengers movies are central in this network. Indeed, they are bigger and linked with stronger arches to each other film. Moreover, they are not only more prominent and more linked with the other films, but they are also at the center of the network. This means that the other movies, even if they were released later, are building on them. This is the typical strategy of a platform where the link among different elements allows the other to benefit from the mutual existence. 
After a qualitative interpretation, we also looked at structural measurements of the network dimension. The results obtained with this analysis underlined that the number of linked nodes is very high. The average degree centrality of the total network is 15,565, having 23 nodes. Thus, the centrality is really high, and this is confirmed also by the graph density that it is not so far from 1 (actual value 0.708 ). So, the network is near to completion and the actual connections are not so different from the potential ones. Another interesting piece of information emerging from the analysis is the fact that, although the network is composed by a lot of nodes, the average path length is only 1,292. Coherently, it emerges that the degree centrality of "Avengers: Endgame" (22), "Avengers: Infinity War" (22) are the highest in the dataset, followed by the others collective movies, like "Captain America: Civil war" (21), "Avengers: Age of Ultron" (20) and "The Avengers" (20), showing the adopted platform strategy.

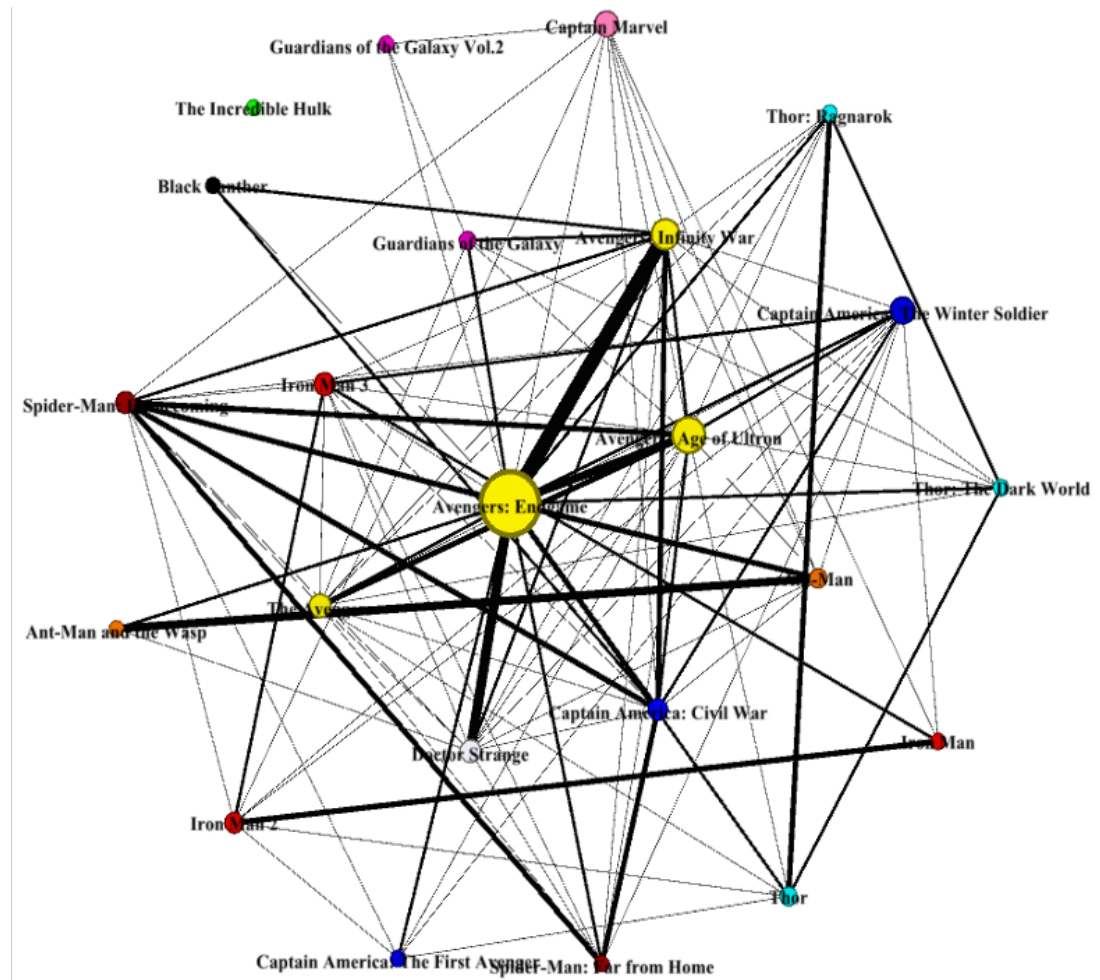

Figure 2 - Network graph of Marvel Cinematic Universe

\section{The DC independency}


Looking at Figure 3, we can see the representation of the network of the DC franchise. What is immediately evident is the fact that the links among the different films are less present. For example, the Green Lantern movie does not have any connections with other characters, items, or locations, belonging to the DC franchise; it is an independent initiative. In other words, there is not a common knowledge base upon which all the movies refer to. This, similarly, to two other movies, Jonah Hex and Catwoman, shows how DC, in its 20 years of history, has not leveraged platform solutions. The only links existing are the ones attached to the Batman trilogy and initiatives like Batman vs. Supermen, where different film characters, items and locations converge. Therefore, we can conclude that DC did not pursue a platform strategy, but has preferred a more independent initiative carried out under the same producer.

The graph density is very low (0.353) and also the average degree shows that the numbers of connections are few $(5,647)$ out of 17 films. The average path length seems to be good $(1,273)$, but it must be considered that five nodes in the network have no relation with anyone; therefore, it is not so efficient as it seems from the value. Finally, the movies that had the best results at the box office have a very low centrality degree: "Aquaman" (3), "Joker" (6), the "Dark Knight" trilogy (6). Thus, these numbers seem to suggest that there is no platform strategy. Still, slightly higher numbers appear in some of the latest releases (“Batman VS Superman" (11), "Suicide Squad" (10), and "Justice League" (11)), showing that a platform strategy may be followed in the next steps. 


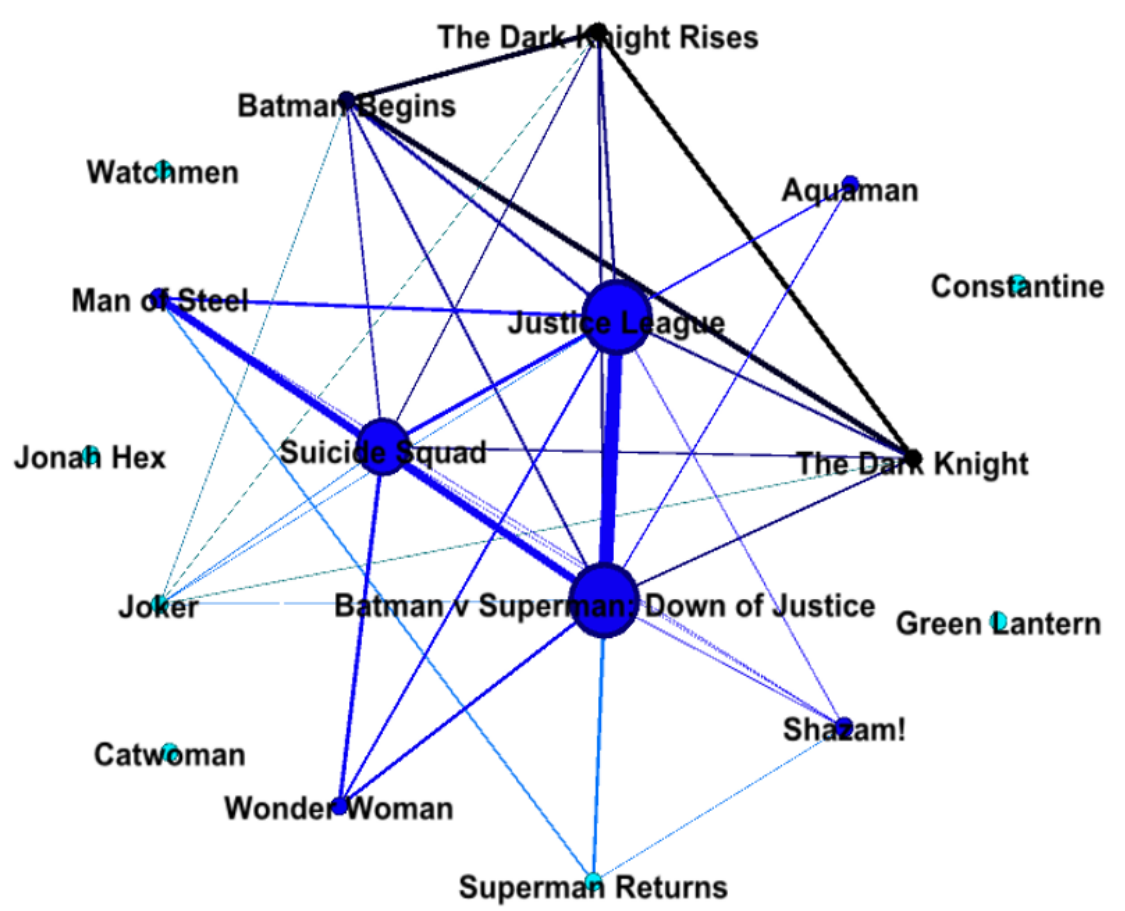

Figure 3 - Network graph of DC

\section{The X-Men Bet}

The X-Men franchise has a different network compared to the Marvel Cinematic Universe. Indeed, the fact that the nodes have almost the same dimensions seems to imply that one is not more relevant than the others in the network, even if they are all almost related to each other. Therefore, even if they show a good network of relations there are no central nodes that prevail. Thus, the analysis of the graphs shows that the franchise decided to connect the different films intensively in terms of characters and less with items and locations, as reported in Figure 4. Considering the absence of central relevant nodes and less tight links among items and locations, the strategy adopted here seems to be a less platform-oriented solution.

The structural measurements have confirmed what we noticed before. The X-Men network is very similar to the MCU network. Moreover, the numbers seem to be even better than the ones obtained in the MCU network. The total network has the maximum value of the average degree centrality, 11 out of 12 films, and the graph density turned out to be 1 similarly to the 
path length, meaning that there is a high level of cohesion in the network. These numbers are supporting the assumption made in the sampling: this looks like a hybrid structure. The numbers are high, suggesting a platform strategy. Nevertheless, they are basically perfect. In other words, all the movies build on all the previous movies in a continuous sequence: all the movies have the same centrality.

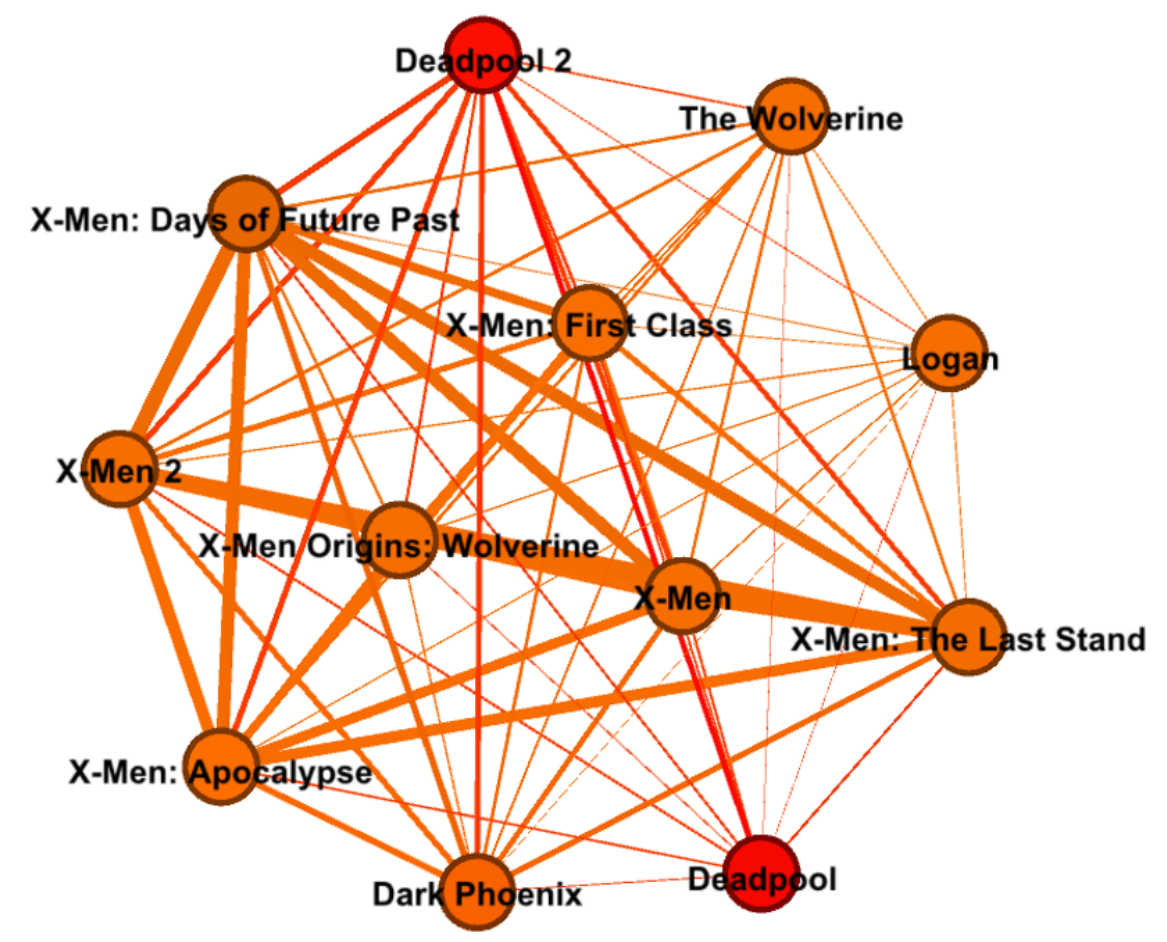

Figure 4 - Network graph of X-Men

\section{The knowledge platform is the way to succeed in the creative industry}

The third analysis that we conducted to comprehend the results achieved by the Marvel Cinematic Universe and the other two franchises regards the statistical analysis to see and prove if there is a statistical significance between the strategy adopted and the box office results. Indeed, the two previous qualitative analyses of the box office and the network analysis seems to indicate that MCU was outperforming compared to the two other franchises because of the existence of the platform strategy. This was shown by the 
performance at the box office and the strong network shown in Figure 2 . Therefore, by adopting an ANOVA analysis between the strategy adopted and the box office results, it emerged that the Marvel strategy (2) is significantly different from DC (0) and X-Men (1) (confirmed by the post-hoc analysis), see Tables 3 and 4 . This means that the strategy explains statistically the success achieved by the company at the box office. Thus, the adoption of a platform strategy seems to support the success of initiatives also in the creative industry.

\begin{tabular}{|l|l|l|l|l|l|}
\hline $\begin{array}{l}\text { Platform } \\
\text { Approach } \rightarrow \text { Box } \\
\text { Office Results }\end{array}$ & Sum of squares & gl & Mean & F & Sign \\
\hline Between groups & 2430611.26 & 2 & 1215305.63 & 5.951 & .005 \\
\hline Within groups & 10006335.4 & 49 & 204210.926 & & \\
\hline Total & 12436946.6 & 51 & & & \\
\hline
\end{tabular}

Table 3 - ANOVA: Platform Strategy $\rightarrow$ Box Office Results

\begin{tabular}{|c|c|c|c|c|}
\hline $\begin{array}{ll}\text { (I) } & \text { Platform } \\
\text { Approach } & \\
\end{array}$ & $\begin{array}{ll}\text { (J) } & \text { Platform } \\
\text { Approach } & \\
\end{array}$ & $\begin{array}{l}\text { Difference from the } \\
\text { man (I-J) }\end{array}$ & Standard error & Sign \\
\hline \multirow[t]{2}{*}{0 (DC) } & 1 & 81.53814 & 170.38188 & .634 \\
\hline & 2 & -397.3596 & 144.53769 & .008 \\
\hline \multirow[t]{2}{*}{1 (X-Men) } & 0 & -478.89775 & 170.38188 & .634 \\
\hline & 2 & -81.53814 & 160.92331 & .005 \\
\hline \multirow[t]{2}{*}{2 (MCU) } & 0 & 397.3596 & 144.53769 & .008 \\
\hline & 1 & 478.89775 & 160.92331 & .005 \\
\hline
\end{tabular}

Table 4 - Post-Hoc analysis: Platform Strategy $\rightarrow$ Box Office Results

\section{Discussion: Defining the Knowledge Platform Strategy}

MCU, X-Men and DC Comics seemed to base their success on three different approaches to platforms and our data proved them. The first, Marvel, is actually building a platform: a set of movies (the stand-alone of the original Avengers) representing the knowledge foundations upon which they built the Infinity Saga, showing the power of the platform from its first collective movie: The Avengers (2012). From that moment on, each movie built on the previous to create a virtuous knowledge cycle that let them reinforce the central movies (until the last "Avengers: Endgame" was able to get the top of the charts of the top grossing movies in history) and the peripherical movies, adding new lines that revitalize the platform (like Black Panther and Captain Marvel). 
Differently, DC did not rely on a platform strategy, having a lot of movies - potentially connected - but that were building their own stories.

While X-Men appears to have a hybrid approach, they were actually telling a long sequential story. The assumptions made in the sampling phase have been confirmed by the empirical results and by the network analysis, showing a greater density in the MCU movies.

The first two comments on these results reinforce previous evidence in the literature on platforms. On the one hand, networks proved their power in mapping platforms (Baldwin and Woodard, 2009; Pellizzoni et al, 2019). On the other, platforms proved their impact on the market - in this case measured through the box office - also in the creative industry, reinforcing the literature that sustains their disruptive power (Choudary et al., 2016). Still, what these observations let emerge is that $\mathrm{MCU}$ is a peculiar kind of platform, sharing some elements with all the concepts previously mentioned, but at the same time not fitting perfectly - any of those definitions.

Is the MCU an internal platform, an industrywide/innovation platform or a transaction/multisided platform? In the remaining part of this paper, we'll provide an answer to this question by comparing the literature on these kinds of platforms with the empirical evidence that emerged from the MCU and defining it as a case of "Knowledge Platform Strategy".

Internal platforms represent the common basis upon which a firm can foster innovation enhancing a standard set of assets (Wheelwright and Clark, 1992; Kogut and Kulatilaka, 1994; Kim and Kogut, 1996; Meyer and Lehnerd, 1997). Like the basic architectures of the Sony Walkman, Marvel created a common world; a common set of characters, places and items upon which they can create new products; and new franchises. Similarly, to this kind of platform, the investment made to create the platform will have returns over time (Sanderson 
and Uzumeri, 1995), and not only with the single product. Therefore, MCU shares some characteristics with internal platforms.

Proposition 1: The Knowledge Platforms Strategy enable the creative firm to create a common world where to build new products and franchises, making a long-term investment, similarly to internal platforms.

Nevertheless, there is a huge difference: internal platforms are "components" and not complete products (Gawer and Cusumano, 2014), while the components in this case are the original movies (Iron Man, Hulk, Thor and Captain America) that created the knowledge basis for the first collective movie: The Avengers. This consideration pushes forwards a comparison with industry-wide platforms (Gawer and Cusumano, 2014) or more broadly innovation platforms (Cusumano et al., 2019). Indeed, the iPhone or the computer (previously mentioned with the example of Intel, Microsoft and IBM) are working products (like the four previously mentioned movies), upon which something new can be built. Indeed, on this basic structure, collective movies can be created, but also new derivates like Black Panther or Captain Marvel. This is closer to the second type of platforms. These platforms are characterized by indirect or cross-sides network externalities: the more complements added to the platform, the more it is going to be valuable for the end-users and vice-versa. This mechanism is difficult to see, since we do not really have "sides", but we are complements that become part of the "platform". Still, the more the initial platform is valuable, the more it is going to be valuable to add new complements. This is shown by the increased impact of the new characters launched, which - in the last two cases (Black Panther and Captain Marvel) - brought about first stand-alone movies able to gross more than $\$ 1$ billion. 
Proposition 2: The Knowledge Platform Strategy uses finished products as the basic modules upon which to build the platform strategy, representing the basic knowledge structure upon which launching new derivatives, generating network externalities as in industry wide platforms.

Nevertheless, also in this case we can highlight a significant difference: the role of network externalities. Still, this virtuous cycle does not exactly exemplify cross-side network externalities (Katz and Shapiro, 1985) for two main reasons: first, there is no second side of external complementors, and second, the complementors enter the platform continuously rather working "on top of it", as it happens with software and apps in previous examples. Finally, moving to transaction and multi-sided platforms (Cusumano et al., 2019), we can again highlight a couple of similarities. First, the strong diffusion curve that can be seen in the box office curves (Figure 1), and the great impact to the market that recalls the impact of disruptors based on a multi-sided structure (Choudary et al., 2016). The chance to add the basic structure and customers, to exploit its value by adding new streams, is much more coherent with the supply-side extension's strategy of multi-sided platforms, which can capture more value once the platform is launched, like Airbnb launching the Experiences (Trabucchi and Buganza, 2020). A possible example here is the usage of original series created in the MCU used to launch the Disney + initiatives. Starting in 2020, Marvel will release add on series (like WandaVision or Loki), integrating with the main plot developed through the 22 movies, through the streaming service Disney +. This is a case of "knowledge" exploitation: the common basis created with the movies is further exploited generating a new product line that is generating revenues through a different initiative (the subscription to Disney + ). 
Proposition 3: The Knowledge Platform Strategy requires a significant initial investment, but offers the chance to develop multiple parallel projects once the "critical knowledge mass" is reached.

Also, in this case, a huge difference: the chicken and egg (Caillaud and Jullien, 2003) paradox is not present, since this platform is created as a set of stand-alone movies, but it enhances the launch of the following movies by building on what happened before.

In conclusion, this section summarizes the points of commonalities and differences between the MCU platform and the three types of platforms that emerge from the literature. MCU is a platform and shows the chance to leverage the power of platforms also in creative industries, but probably it needs a proper label: it is a "Knowledge Platform Strategy" (Figure 5). The platforms is built about a knowledge network made of stand-alone creative contents that create the basic structure upon which new content is provided leveraging and expanding the knowledge put it in the platform.

Similarities
$\begin{gathered}\text { Internal Platforms } \\ \text {-There is a common base upon } \\ \text { which to build further releases } \\ \text {-The investments are going to have } \\ \text { a return also with future releases }\end{gathered}$
$\begin{gathered}\text {-The initial platform (first movies) } \\ \text { is a "working product" }\end{gathered}$
$\begin{gathered}\text { Innovation Platforms } \\ \text {-The more the platform grows, the } \\ \text { more valuable it becomes }\end{gathered}$
Transactional Platforms
-Increasing returns after the
"critical mass" is reached
-Continuous extension and
modularity

Differences
-An internal platform is usually made
of "components" or of "a basic
structure". In this case, the
components are stand-alone movies
-Industry-wide platforms have
"cross-side" network externalities. In
this case a "virtuous cycle" has been
created
-Multi-sided platforms suffer from the
"chicken and egg" paradox. In this case
launching the platform (initial movies)
equals launching products

Figure 5 - Knowledge platform strategy and its similarities and differences with internal, industry wide and multi-sided platforms 
The three propositions let also emerge a process view on the creation and exploitation of a Knowledge Platform Strategy, which integrates the view of the different definitions of platforms showed in the literature (Figure 6).

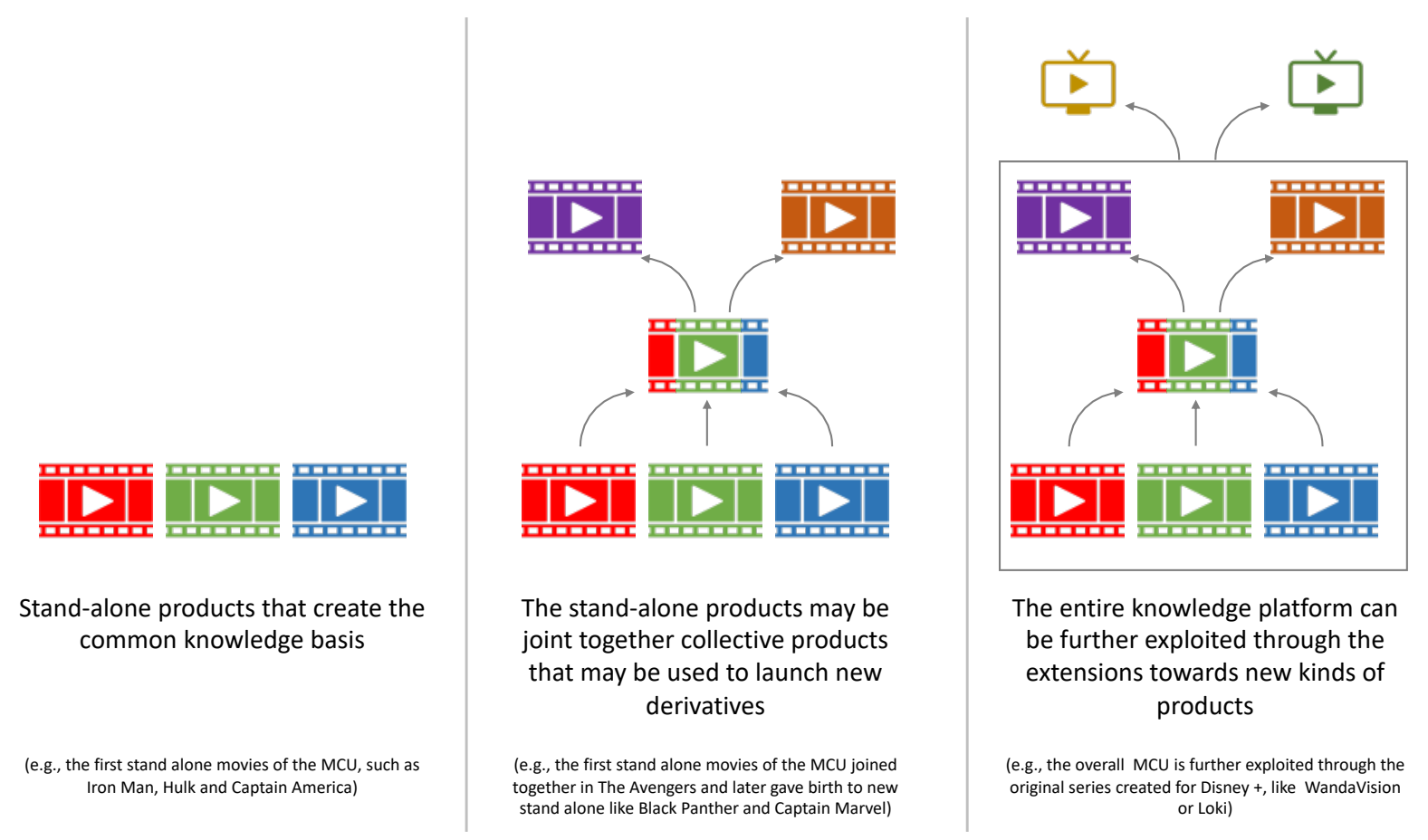

Figure 6 - Knowledge platform strategy and it longitudinal view

\section{Conclusion: What Superheroes Can Teach us about Designing}

\section{Platforms}

Superheroes have had a super impact on the box office during the last decade, but the three most successful franchises seemed to have adopted very different approaches. MCU built a platform, movie after movie, upon which everything relies, and new movies can be launched. X-Men built a list of sequential movies. DC created disjointed movies, leveraging sequels in some cases and only in recent years linking some movies together. The peculiarities of this industry let us explore the potential impact of platform strategies in creative industry and this study has two main contributions. 
This study explores a mature and relevant concept - the platforms - in a new filed, the creative industries using the case of Superheroes sagas, proposing a new perspective to explain the success of MCU, while proposing the "Knowledge Platform Strategy".

In terms of theoretical contribution, this research extends the concept of "platforms", relying on the three kinds of platform defined in the managerial literature (e.g., Gawer and Cusumano, 2014; Trabucchi and Buganza, 2020; Cusumano et al., 2019) and introducing the "Knowledge Platform Strategy" for creative industries. The main contribution is related to the extension of platforms in research fields where it has not been exploited. This opens up avenues for research both from a knowledge platform and creative industries perspectives. In other words, it supports the literature presenting the power and impact of the platform paradigm, also in creative industries and not just in the digital environment.

From a managerial viewpoint, it suggests the concept of "Knowledge Platform Strategy" to managers working in creative industries, but no only. This label has been inspired by various definitions of platforms, but fits the peculiar case of all the industries where a common knowledge base may be valuable for the customers and for the development of new products. A "Knowledge Platform Strategy" is an approach that may help managers in rethinking the development process or the knowledge management strategy. In a creative industry it means that a set of characters, story lines and places can be built through various stand-alone products (in this case movies, more broadly products) creating a knowledge base upon which future content will build on. Their links offer the chance to build common collective products (like The Avengers) that exploit the value of the interest collected with all the single components. Then, the platform can be exploited by using it to launch new streams, new sets of characters, storylines and places that will become part of the common ground of the platform and help it enter a virtuous cycle that lets it expand in various directions. 
Obviously, this research is not free of limitation. It is an exploratory study focusing on a very peculiar case, that let emerge an interesting and new strategy. It needs to be noted how all the three cases analyzed can be considered successful from a market perspective, and how single products (such as Joker, or the Batman Trilogy) are considered high-quality products. In other words, the knowledge platform strategy is definitely not the only way to be successful, but seems to offer great insights for a sustainable and overtime impact. Nevertheless, the approach and the case under observation may open up direction for new studies. Future avenues for research may consider the translation of this "Knowledge Platform Strategy" in different creative industries, or even in other knowledge-based industries. It may be interesting to replicate the analysis on the market impact on other cases. It may be very interesting also to study possible reactions to the COVID-19 emergency, which had huge impacts in the movie industry (with many movies delayed both in terms of production and release), it may be interest to understand if and how a platform strategy may help. Furthermore - in terms of qualitative research - it would be interesting to study the coordination mechanisms and alignments rules that companies use to build this kind of platforms.

This is not new in the world of Superheroes, where both MCU and DC comics have been published following the same logic. Still, it shows that the relevance of platforms goes far beyond the speed of Uber and Airbnb, and gives superpowers even to superheroes.

\section{References}

Amit, R. \& Han, X. 2017, "Value creation through novel resource configurations in a digitally enabled world", Strategic Entrepreneurship Journal, .

Andriani, P. \& Carignani, G., 2014. "Modular exaptation: A missing link in the synthesis of artificial form", Research Policy, vol. 43, no. 9, pp.1608-1620. 
Artusi, F. and Bellini, E. (2020), "Design and the customer experience: the challenge of embodying new meaning in a new service", Creative Innovation Management, pp. 1-10, doi: 10.1111/caim.12364.

Antonacci, G., Colladon, A.F., Stefanini, A. \& Gloor, P. 2017, "It is rotating leaders who build the swarm: social network determinants of growth for healthcare virtual communities of practice", Journal of Knowledge Management, .

Arenas-Márquez, Francisco José, M. Rocío Martínez-Torres, \&S. L. Toral. 2014. “Electronic Word-of-Mouth Communities From the Perspective of Social Network Analysis", Technology Analysis \& Strategic Management vol. 26, no. 8, pp. 927-942.

Baldwin, C.Y. \& Clark, K.B. 2003, "Managing in an age of modularity", Managing in the modular age: Architectures, networks, and organizations, vol. 149, pp. 84-93.

Baldwin, C.Y. \& Woodard, C.J. 2009, "The architecture of platforms: A unified view", Platforms, markets and innovation, vol. 32.

Beltagui, A., Rosli, A. \& Candi, M., 2020. "Exaptation in a digital innovation ecosystem: The disruptive impacts of 3D printing", Research Policy, vol. 49, no. 1, p.103833.

Bonchek, M., \& Choudary, S. P. 2013, "Three elements of a successful platform strategy", Harvard Business Review, vol. 92 no. 1-2.

Brillinger, A. S., Els, C., Schäfer, B., \& Bender, B. (2020). Business model risk and uncertainty factors: Toward building and maintaining profitable and sustainable business models. Business Horizons, vol. 63, no. 1, pp. 121-130.

Caillaud, B. \& Jullien, B. 2003, "Chicken \& egg: Competition among intermediation service providers", RAND journal of Economics, , pp. 309-328.

Choudary, S.P., Parker, G.G. \& Van Alstyne, M.W. 2016, Platform Revolution: How Networked Markets Are Transforming the Economyand How to Make Them Work for You, WW Norton \& Company.

Cusumano, M.A., Yoffie, D.B. \& Gawer, A. 2019, The Business of Platforms: Strategy in the Age of Digital Competition, Innovation, and Power, HarperCollins Publishers.

Donthu, N., Kumar, S., \& Pattnaik, D., 2020. "Forty-five years of Journal of Business Research: A bibliometric analysis", Journal of Business Research, vol. 109, pp. 1-14.

Downes, L. \& Nunes, P. 2014, Big bang disruption: Strategy in the age of devastating innovation, Penguin.

Evans, D.S. \& Schmalensee, R. 2010, "Failure to launch: Critical mass in platform businesses", Review of Network Economics, vol. 9, no. 4.

Evans, D.S. \& Schmalensee, R. 2016, Matchmakers: The New Economics of Multisided Platforms, Harvard Business Review Press.

Franzoni, C. \& Sauermann, H., 2014. "Crowd science: The organization of scientific research in open collaborative projects", Research policy, vol. 43, no. 1, pp.1-20. 
Gabriel, Y., 2000. Storytelling in organizations: Facts, fictions, and fantasies: Facts, fictions, and fantasies. OUP Oxford.

Garud, R., Gehman, J., \& Giuliani, A.P., 2014. “Contextualizing entrepreneurial innovation: a narrative perspective", Research Policy, vol. 43, no. 7, pp. 1177-1188.

Gawer, A. \& Cusumano, M.A. 2014, "Industry platforms and ecosystem innovation", Journal of Product Innovation Management, vol. 31, no. 3, pp. 417-433.

Hagiu, A. \& Wright, J. 2015, "Multi-sided platforms", International Journal of Industrial Organization, vol. 43, pp. 162-174.

Harrison, S., Carlsen, A. \& Skerlavaj, M. 2019, "Marvel's blockbuster machine: How the studio balances continuity and renewal", Harvard Business Review, vol. 97, no. 4, pp. 136.

Hu, Yuanjia, Thomas Scherngell, Lan Qiu, \&Yitao Wang. 2015. "R\&D Internationalisation Patterns in the Global Pharmaceutical Industry: Evidence From a Network Analytic Perspective", Technology Analysis \& Strategic Management, vol. 27, no. 5, pp. 532-549.

IMDB 2020, "Top Lifetime Grosses", Box Office Mojo by IMDB Prof, vol. Accessed March 16th, 2020.

Kaplan, A. M., \& Haenlein, M. (2010). Users of the world, unite! The challenges and opportunities of Social Media. Business horizons, 53(1), 59-68.

Katz, M.L. \& Shapiro, C. 1985, "Network externalities, competition, and compatibility", The American Economic Review, vol. 75, no. 3, pp. 424-440.

Kim, D.-. \& Kogut, B. 1996, "Technological Platforms and Diversification", Organization Science, vol. 7, no. 3, pp. 283-301.

Kogut, B. \& Kulatilaka, N. 1994, "Options thinking and platform investments: Investing in opportunity", California management review, vol. 36, no. 2, pp. 52-71.

Landoni, P., Dell'era, C., Frattini, F., Petruzzelli, A. M., \& Manelli, L. 2020, "Business model innovation in cultural and creative industries: Insights from three leading mobile gaming firms". Technovation, vol. 92-93, no 2.

Latilla, V.M., Frattini, F., Petruzzelli, A.M. \& Berner, M. 2018, "Knowledge management, knowledge transfer and organizational performance in the arts and crafts industry: a literature review", Journal of Knowledge Management.

Latilla, V.M., Frattini, F., Petruzzelli, A.M. \& Berner, M. 2019, "Knowledge management and knowledge transfer in arts and crafts organizations: evidence from an exploratory multiple case-study analysis", Journal of Knowledge Management.

Magistretti, S., Dell'Era, C., \& Petruzzelli, A. M. (2019). How intelligent is Watson? Enabling digital transformation through artificial intelligence. Business Horizons, 62(6), 819-829.

Malhotra, A. \& Majchrzak, A. 2019, "Greater associative knowledge variety in crowdsourcing platforms leads to generation of novel solutions by crowds", Journal of Knowledge Management, .

Meyer, M.H. \& Lehnerd, A.P. 1997, The power of product platforms, Simon and Schuster. 
Miles, M.B. \& Huberman, A.M. 1984, "Drawing valid meaning from qualitative data: Toward a shared craft", Educational researcher, vol. 13, no. 5, pp. 20-30.

Muzellec, L., Ronteau, S. \& Lambkin, M. 2015, "Two-sided Internet platforms: A business model lifecycle perspective", Industrial Marketing Management, vol. 45, pp. 139-150.

Parker, G.G. \& Van Alstyne, M.W. 2005, "Two-sided network effects: A theory of information product design", Management Science, vol. 51, no. 10, pp. 1494-1504.

Pellizzoni, E., Trabucchi, D. \& Buganza, T. 2019, "Platform strategies: how the position in the network drives success", Technology Analysis \& Strategic Management, vol. 31, no. 5, pp. 579-592.

Pentland, B.T., 1999. "Building process theory with narrative: From description to explanation", Academy of management Review, vol. 24, no. 4, pp.711-724.

Randhawa, K., Josserand, E., Schweitzer, J., \& Logue, D. (2017). Knowledge collaboration between organizations and online communities: the role of open innovation intermediaries. Journal of Knowledge Management.

Renfro, P. M. (2020). Stranger Danger: The Politics of Child Protection from Etan Patz to AMBER Alert. Oxford University Press, USA.

Rifkin, J. (2014). The zero marginal cost society: The internet of things, the collaborative commons, and the eclipse of capitalism. St. Martin's Press.

Rochet, J. C., \& Tirole, J. (2003). Platform competition in two-sided markets. Journal of the european economic association, 1(4), 990-1029.

Salkowitz, R. (2018). Economic realism in the worlds of Alan Moore. In Superheroes and Economics (pp. 1-12). Routledge.

Sanasi, S., Ghezzi, A., Cavallo, A. \& Rangone, A. 2020, Making sense of the sharing economy: a business model innovation perspective. Technology Analysis and Strategic Management.

Sanderson, S., \& Uzumeri, M. (1995). Managing product families: The case of the Sony Walkman. Research policy, 24(5), 761-782.

Saragih, H. 2019, "Co-creation experiences in the music business: a systematic literature review", Journal of Management Development.

Savino, T., Petruzzelli, A.M. \& Albino, V. 2017, "Teams and lead creators in cultural and creative industries: evidence from the Italian haute cuisine", Journal of Knowledge Management.

Scott, J. 2000. "Social Network Analysis: the handbook". 2nd ed London; Thousands oaks, Calif, SAGE Pubblications Ltd, 2000.

Täuscher, K. (2017). Leveraging collective intelligence: How to design and manage crowdbased business models. Business Horizons, 60(2), 237-245.

Trabucchi, D. \& Buganza, T. 2020, "Fostering digital platform innovation: From two to multisided platforms", Creativity and Innovation Management, . 
Trabucchi, D. 2020, "Let's Get a Two-Sided Platform Started: Tactics to Solve the Chicken and Egg Paradox", Journal of Business Ecosystems (JBE), vol. 1, no. 1, pp. 63-77.

Trabucchi, D., Pellizzoni, E., Buganza, T. \& Verganti, R. 2017, "Interplay between technology and meaning: how music majors survived?", Creativity and Innovation Management, vol. 26, no. 4.

Trabucchi, D., Muzellec, L., \& Ronteau, S. 2019. "Sharing economy: seeing through the fog", Internet Research, vol. 29, no. 5, pp. 996-1013.

Verganti, R., Vendraminelli, L., \& lansiti, M. 2020, "Innovation and Design in the Age of Artificial Intelligence". Journal of Product Innovation Management, vol. 37, no. 3, pp. 212227.

Wasserman, S., \& Faust, K. 1994. "Social network analysis: Methods and applications" (Vol. 8). Cambridge university press.

Watts, A. 2003. "A dynamic model of network formation". In Networks and Groups (pp. 337345). Springer Berlin Heidelberg.

Wheelwright, S.C. \& Clark, K.B. 1992, Creating project plans to focus product development, Harvard Business School Pub. 